If an HI titre of 48 or less indeed indicates potential susceptibility then the results of this study suggest that people in a high-risk category should be strongly encouraged to undertake a two-dose vaccination schedule annually, especially when a new influenza strain has arisen by antigenic drift, and they should receive their first dose of vaccine within two to four months of the normal seasonal epidemic period. It may be fallacious to judge the effectiveness of a vaccine in terms of antibody persistence within a population by the height of geometric mean HI titres. Such titres may reflect an inflated level of immunity by assessing a population rather than the antibody status of individuals within the population.

I thank Mrs Isobel MacKenzie and Mrs Julie Lloyd for their excellent technical help. This study was supported by grants from the National Health and Medical Research Council of Australia and Smith Kline and French Laboratories (Australia) Ltd.

\section{References}

${ }^{1}$ Eickhoff, T C, Fournal of Infectious Diseases, 1971, 123, 446.

${ }^{2}$ Howells, C H L, Evans, A D, and Vesselinova-Jenkins, C, Lancet, 1973, $1,1436$.

3 Picciotto, L, et al, British Medical fournal, 1973, 4, 169.

${ }^{4}$ Hobson, D, Baker, F A, and Curry, R L, Lancet, 1973, 2, 155.

5 Feery, B J, et al, Medical fournal of Australia, 1976, 1, 186.

${ }^{6}$ MacKenzie, J S, Medical fournal of Australia, 1976, 1, 546.

${ }^{7}$ MacKenzie, J S, et al, Fournal of Hygiene, 1975, 75, 425.

${ }^{8}$ Dauer, C C, and Serfling, R E, American Review of Respiratory Diseases, 1961, 83, suppl p 15.

${ }^{9}$ Eickhoff, T C, Sherman, I L, and Serfling, R E, fournal of the American Medical Association, 1961, 176, 776.

10 Marine, W M, and Thomas, J E, Postgraduate Medical Fournal, 1973, 49, 164

11 Evans, A S, Jeffrey, C, and Niederman, J C, American fournal of Epidemiology, 1971, 93, 463.

12 Hobson, D, et al, fournal of Hygiene, 1972, 70, 767.

(Accepted 18 November 1976)

\title{
Intrauterine deposition of calcium on copper-bearing intrauterine contraceptive devices
}

\author{
CHRISTINE GOSDEN, ALAN ROSS, NANCY B LOUDON
}

British Medical Fournal, 1977, 1, 202-206

\section{Summary}

Copper-bearing intrauterine contraceptive devices (IUDs) removed after various times in utero were examined by scanning electron microscopy and x-ray microanalysis of the elements present. As time in utero increased these devices became increasingly calcified. This calcification may limit the release of copper from the devices and decrease the specific contraceptive effectiveness of copper over an inert plastic device. Conversely, any teratogenic effects attributable to the copper may decrease with time in utero and depend on the extent of calcification.

Even though the amount of copper in the device is not significantly diminished after two years, devices should not remain in situ for over two years because calcium accumulation probably prevents further diffusion of copper. Calcification can begin as early as six months after insertion. Consequently a careful review of the amount of time a copper-containing IUD should be left in situ should be undertaken.

\section{Introduction}

Winding copper wire round an inert plastic intrauterine device (IUD) was found to improve its contraceptive efficiency and

\footnotetext{
MRC Clinical and Population Cytogenetics Unit, Western General Hospital, Edinburgh

CHRISTINE GOSDEN, BSC, PHD, member of scientific staff

ALAN ROSS, FIMLS, MIBIOL, chief research officer

Family Planning Services, Lothian Health Board

NANCY B LOUDON, MB, CHB, senior medical officer
}

reduce side effects. ${ }^{1}$ Available data seemed to indicate an inverse relation between the surface area of the copper and the pregnancy rate. ${ }^{2}$ It is not known how plastic IUDs work, although it has been suggested that they somehow prevent implantation of a fertilised ovum by direct local action on the endometrium. The decrease in pregnancy rate when copper is added suggests an additional contraceptive effect, possibly related to toxic effects on sperm, ovum, and embryo; the effect of copper on endometrial biochemical pathways, thus disturbing implantation; or local inflammatory responses with macrophage stimulation, leucocyte infiltration, and changes in cervical mucus. ${ }^{34}$ Copper released from these devices significantly increases copper concentrations in the intrauterine fluid in the first 12 months, but it does not increase serum copper or caeroplasmin concentrations. ${ }^{5} 6$

Hagenfeld $t^{5}$ found a linear relation between the release rate of copper and the duration of use of the device over the first year. On the graph, however, the line did not pass through the origin, which suggests that there is a higher release rate during early cycles of IUD use. Copper concentrations in the proliferative endometrium were increased during the first three cycles but not thereafter, and the copper concentration of the cervical mucus also increased considerably during the first six treatment cycles, especially during the proliferative phase. The enhanced contraceptive efficiency of the copper IUDs compared with inert plastic IUDs is greatest in this initial period.

Hagenfeldt also measured the amount of copper on the devices by dissolving the metal in concentrated $\mathrm{HNO}_{3}$ and estimating the copper colorimetrically. Intrauterine release rates varied from 7.4 to $13.3 \mathrm{mg}$ of copper in the first year. Given a constant release rate, an average of $28.7 \mu \mathrm{g}$ of copper was therefore released each day. Tatum ${ }^{7}$ suggested that a device's effective life is determined by the time taken to reduce the copper surface area below that required to provide acceptable contraceptive action. Using Hagenfeldt's figures for copper loss, he estimated that this point would be reached when $40 \mathrm{mg}$ of copper had been released. A conservative estimate of the life of a device might therefore be about two years, but this could be extended and a third or fourth year of effective use obtained.

The suggestion that contraceptive efficiency is reduced when 
there is less than a critical amount of copper led us to extend our investigations of copper levels in embryos and fetuses conceived in the presence of IUDs to a study of the devices themselves. If there is a link between copper diffusion rates and conception the amount of copper released at different times might also affect any teratogenic influence of the copper. We studied copper IUDs removed at family planning clinics, and it became apparent that there were profound changes in the IUDs. Gupta et $a l^{*}$ has described the finely granular and irregular moth-eaten appearance of copper IUDs (thought to be due to the effects of copper erosion) and the presence of macrophages, spindle cells, fibroblasts, and giant cells. We used scanning electron microscopy and $x$-ray microprobe analysis to examine the irregular surface more closely.

\section{Methods}

Copper 7 (Gravigard) IUDs were removed from patients during routine visits to family planning clinics. Reasons for removal were: (a) the patient wanted to become pregnant; $(b)$ bleeding or pain, or both, or other medical reasons; (c) routine removal after two to three years' use, based on the suggestion of Tatum. ${ }^{7}$ We thus collected IUDs that had been in utero for varying lengths of time. Some unused IUDs were also studied.

Sterile Sterilin plastic containers were filled with $30 \mathrm{ml}$ of Ham's F10 medium with HEPES buffer supplemented with 50 units $/ \mathrm{ml}$ penicillin and $50 \mathrm{\mu g} / \mathrm{ml}$ streptomycin. The copper $7 \mathrm{~s}$ were placed in the containers immediately after removal and transported to the laboratory for processing. The patient's code number and the dates of insertion and removal of the device were recorded on the container.

The copper 7 is made of inert plastic (polypropylene and polyethylene copolymer) with added barium sulphate and copper wire, $0.203 \mathrm{~mm}$ in diameter, wound round the vertical limb to give a total surface area of $200 \mathrm{~mm}^{2}$ of copper.

Each IUD was examined in the hydrated state with the inverted light microscope. The copper-wound arm was divided into three portions to enable us to study surface morphology and topography, analyse the elements present in intact coils, and measure the diameter and elemental distribution from cross sections.

The portion of IUD for surface topography was transferred from medium to $2.5^{\circ}$ o cacodylate-buffered gluteraldehyde for at least 18 hours, washed in cacodylate buffer, and post-fixed in $1 \%$ osmium tetroxide. Dehydration was carried out using graded acetone, and, finally, the sample was critical-point dried from liquid $\mathrm{CO}_{2}$. This portion of IUD was mounted on an aluminium stub and coated with a $500-\AA$ layer of gold in a Polaron Sputter Coater.

The remaining two portions for cross-sectional measurements of diameter and elemental analyses were allowed to air-dry. One portion was mounted intact on an aluminium stub and the other portion was embedded in Araldite, allowed to polymerise at $60^{\circ} \mathrm{C}$, and cut down the middle to expose the copper wire in cross-section. To obtain a flat surface the blocks were finally trimmed using glass knives in an ultramicrotome. Each part of the device for elemental analysis was coated with carbon in an AEI coating unit using a Polaron Rota Cota.

All specimens were examined in a Cambridge S180 scanning microscope fitted with a Link $x$-ray microanalyser system. The specimen height angle of tilt, and the position of the detector were held constant during $x$-ray microanalysis. The specimen current used was $2.0 \times 10^{-9} \mathrm{~A}$ at a beam energy of $30 \mathrm{keV}$.

\section{Results}

Light microscopy-The unused copper $7 \mathrm{~s}$ had the shining appearance of metallic copper and regular unmarked copper wire coils. IUDs that had been in situ for a few months looked little different from the unused IUDs. Devices that had been in situ for longer showed varying degrees of encrustation on the copper wire, which was blackened. IUDs that had been in situ for two years or more had blackened coils with considerable encrustation proceeding to the state where individual turns of the copper wire were obscured.

Morphology and surface topography on scanning electron microscopyThe surface topography of the portion of the IUDs that had been critical-point dried showed amounts of cellular and amorphous material which increased with the time the device had been in situ. An unused device and a heavily encrusted device that had been in situ for 26 months are shown in fig $1 a$ and $b$. The heavy deposit seen in fig $1 b$ is shown at a higher magnification in fig $1 c$ and consists of amorphous and cellular material.

$\mathrm{X}$-ray microprobe analysis (elemental analysis)-This was carried out on the portion of the coil that had been air-dried and carboncoated. $X$-ray analysis was made of three or four areas (measuring $135 \mathrm{um}^{2}$ ) on each device, and all these regions were counted for two minutes live time. The $x$-ray energy spectra of the elements present were drawn with an X-Y plotter, and integral counts of each of these areas were obtained. Fig 2 shows the spectra of the IUDs whose surface topography was shown in fig $1 a$ and $b$, together with spectra of two other devices that had been in situ for four and 22 months and showed the effect of progressive calcification. Fig 3 shows the percentages of copper, calcium, and other elements from the integral counts of the spectra from 24 copper 7 devices removed after various times in utero. The complementary increase in calcium and decrease of copper with time in utero can be seen clearly. A considerable variation in calcification and cell colonisation between coils of similar ages is also evident, although the trend of increasing calcification with time is clear. The presence of other elements such as chlorine, sulphur, phosphorus, sodium, and potassium may be due to changes of the uterine chemistry, cellular metabolism, and cell type associated with the coil.

Cross sections-Cross sections of each coil were cut to enable the diameter of the copper wire and the distributions of the calcium and copper to be shown. Cross-sections of the copper wire of the 26month specimen are shown in fig $1 d$-f. Fig $1 d$ shows a cross-section of the single strand of copper wire shown in fig $1 c$ and consists of a central core with slight peripheral erosion surrounded by a layer up to $40 \mathrm{um}$ in thickness. The distribution of $x$-rays emitted from calcium (shown by the white spots in fig $1 f$ ) shows that the deposit round the copper wire consists mainly of calcium. In contrast, the elemental distribution for copper (fig $1 e$ ) shows all the copper to be concentrated in the central core with none detectable in the outer calcium layer.

\section{Discussion}

\section{COPPER DIFFUSION AND CALCIFICATION}

The cross-sections of the IUDs showed wide variations in the amount of calcium deposited on the surface of the copper wire. Devices with a thick layer of calcium had central cores of copper with diameters about $200 \mu \mathrm{m}$, which is almost the same as that of the unused copper wire. These devices had only a shallow erosion layer, while those devices with a much thinner calcium layer had much deeper erosion into the copper wire. This indicates that the calcium layer prevents copper diffusion.

Our results show that calcification occurs progressively, and Gibor's data indicate that the rate of release of copper decreases with time. ${ }^{9} \mathrm{He}$ found that the maximum release of copper $(56.5 \mathrm{\mu g} /$ day $)$ was achieved within two months of the insertion of a copper 7. At 12 months this figure was reduced to $19.6 \mu \mathrm{g} /$ day and at 21 months the device was releasing only $8.9 \mu \mathrm{g} / \mathrm{day}-$ a sixfold reduction in copper loss over 22 months. Hagenfeldt's detailed study of copper loss with time covered only the first 12 months of use of the copper T 200, although significantly the maximum copper loss occurred during the first two cycles and was beginning to show a considerable decrease in cycles 11 and 12. Zielske et $a l^{10}$ found a much lower release rate of copper from copper T 200 devices than Hagenfeldt $(20 \mu \mathrm{g} /$ day compared with $45 \mu \mathrm{g} /$ day). They too found a great decrease in copper loss from the devices with time, and, most importantly, they found extremely low copper release values for devices from three women who had conceived with the IUDs in situ.

Most of the reports on pregnancy rates with copper IUDs in situ have covered only the first $12-18$ months of use. It is thus of paramount importance to examine the data of Newton et $a l,{ }^{11}$ who compared results in women who had a new copper 7 inserted at 24 months with those in women who continued to use their copper 7 for a third year. They found that several pregnancies occurred among women who had had the same device in utero for three years. On our hypothesis the device in these women may have calcified, thereby preventing effective 


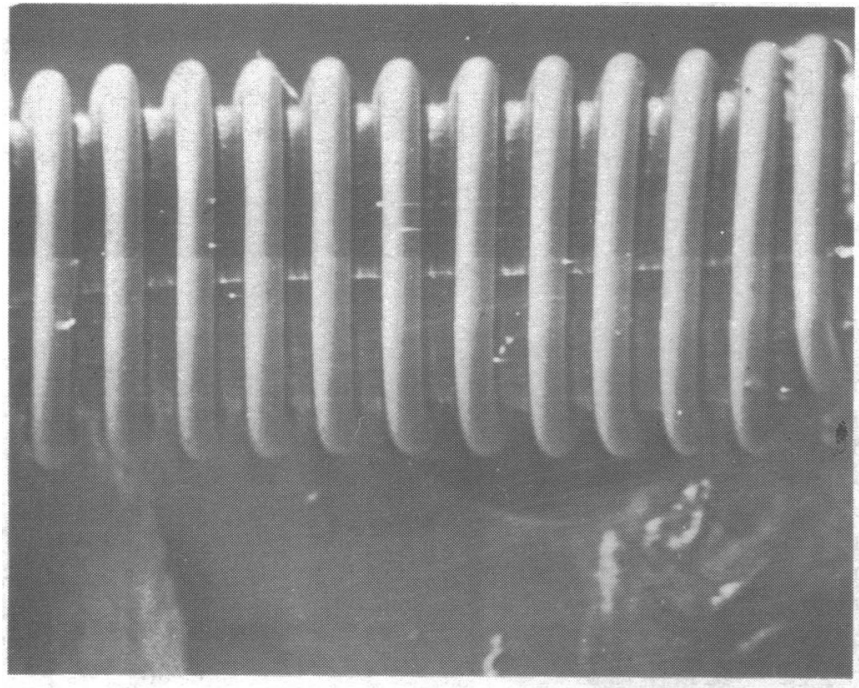

$\underline{a}$

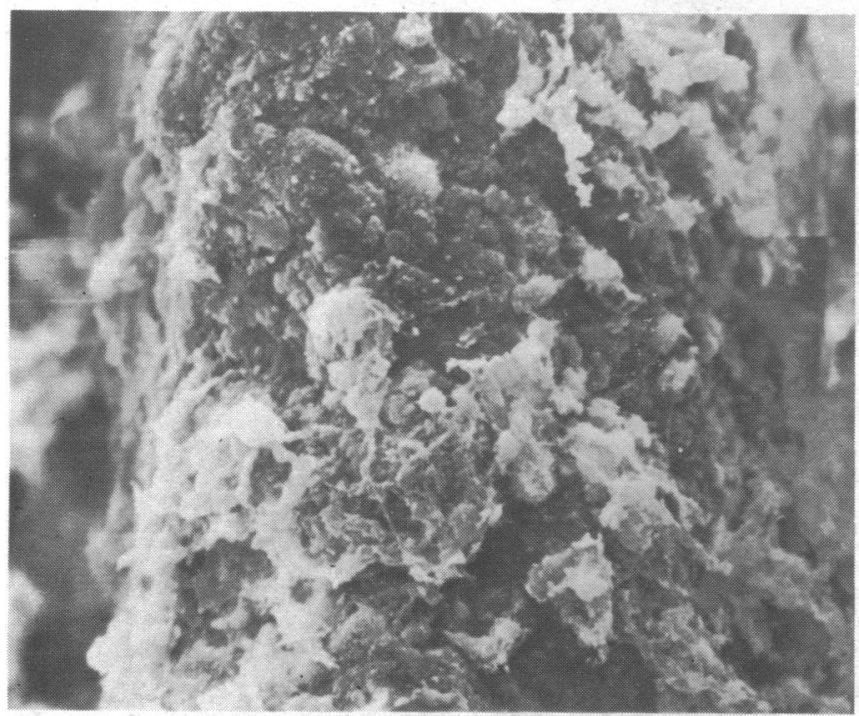

c

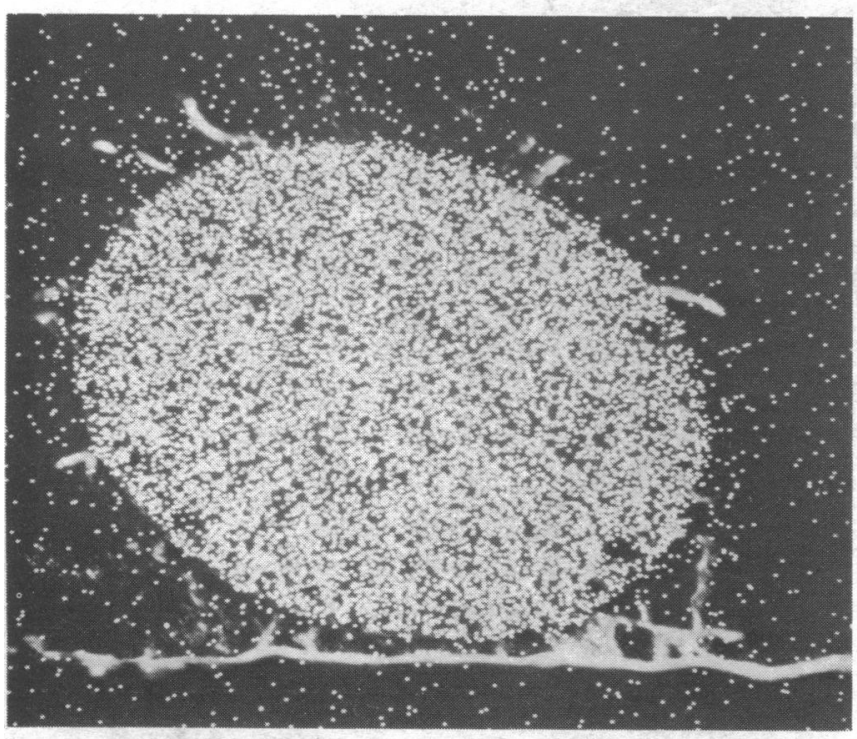

$\underline{e}$
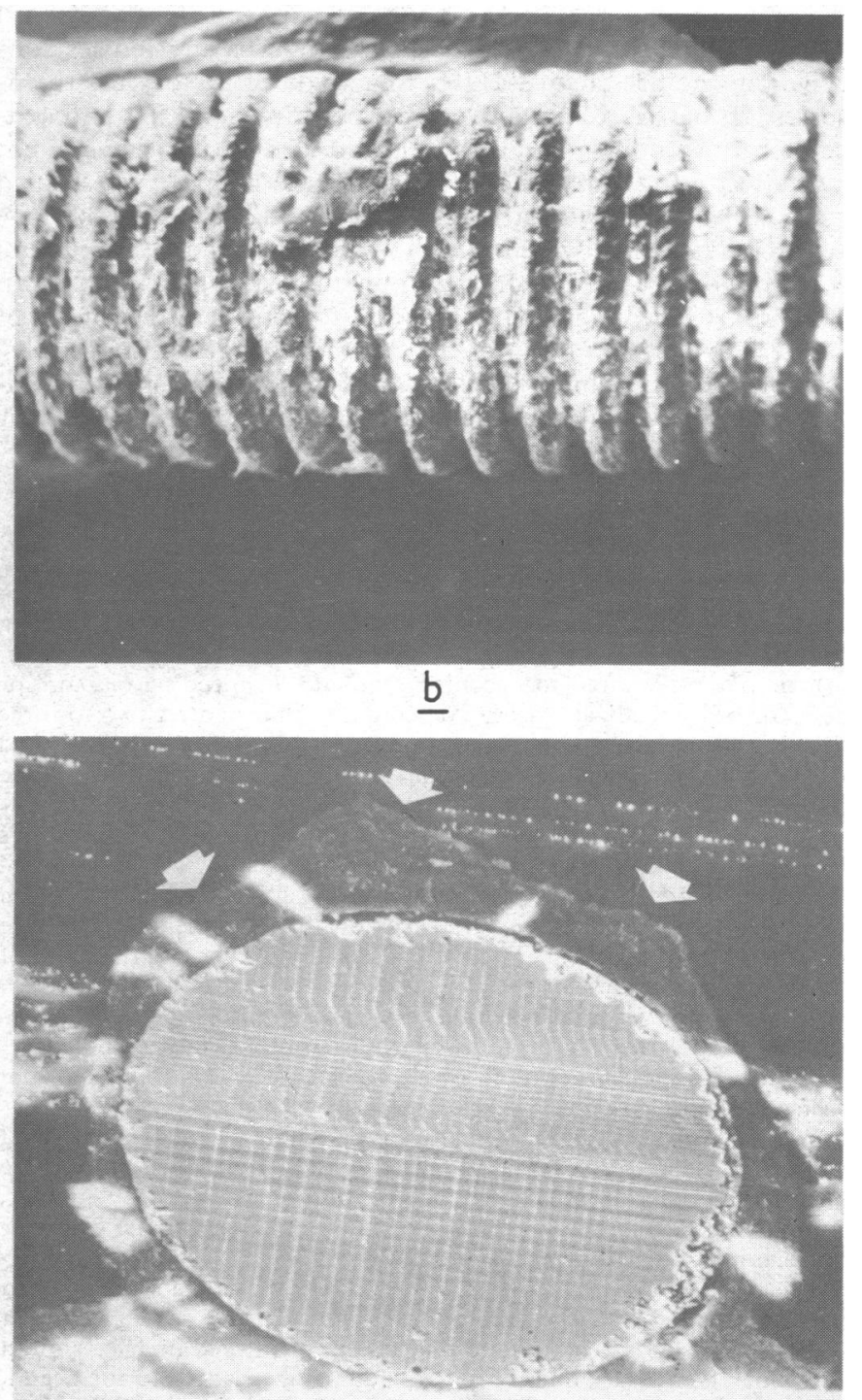

d

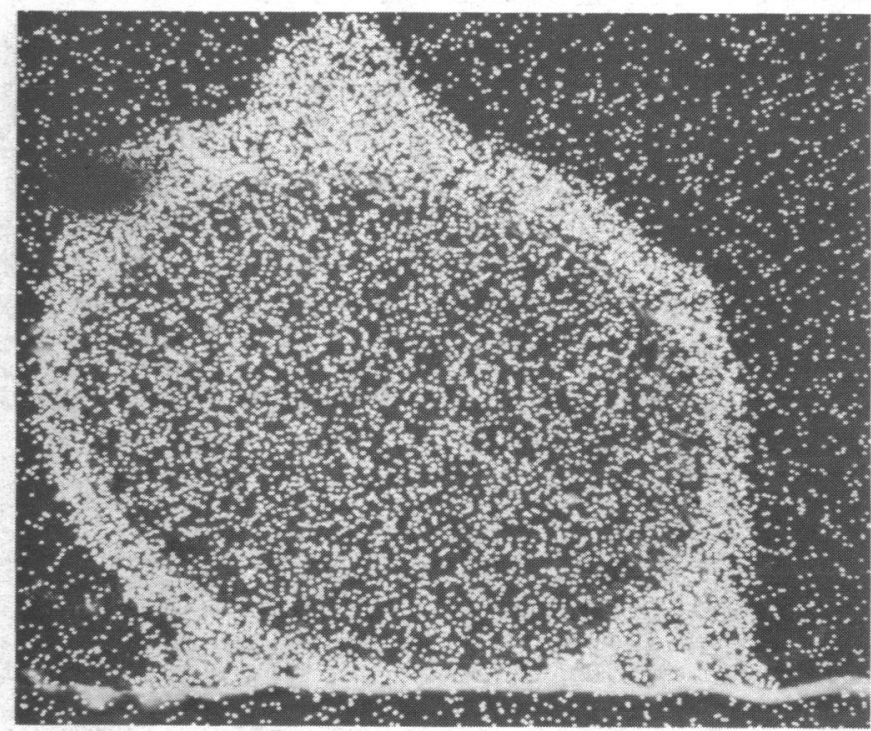

$\underline{f}$

FIG 1-(a) Portion of copper-wound arm of unused copper 7 device. Smooth copper wire coils are shown wound around inert plastic. $(\times 16).(b)$ Part of IUD that had been in utero for 26 months. Thick encrustation covers copper wire as well as inert plastic. $(\times 16).(c)$ Higher power view of one strand of copper wire seen in b. Surface consists of cellular and amorphous material. $(\times 310).(d)$ Cross-section of wire shown in $c$ showing slight erosion around edge of central copper core. Halo around device (arrowed) is encrustation. (e) Same cross-section as seen in $d$ showing distribution of copper. White dots are derived from $x$-rays emitted by copper. Distribution is confined to central area only and no copper is present in outer layer. $(f)$ Same cross-section as in $d$ showing calcium distribution, which is predominantly confined to outer layer. 

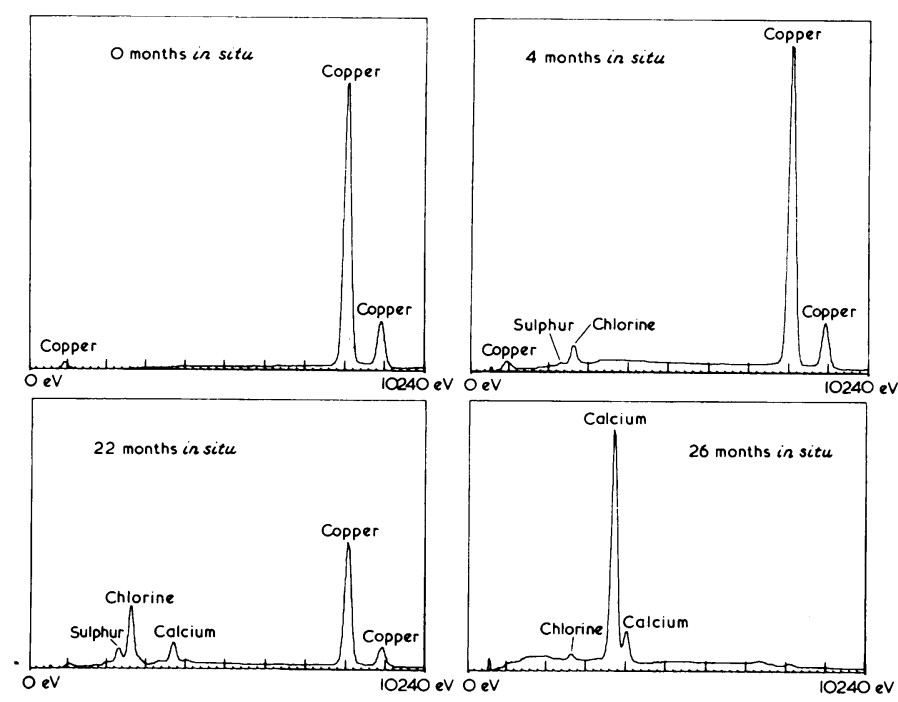

FIG $2-\mathrm{X}$ and $\mathrm{Y}$ plots of $x$-ray emission spectra from copper-bearing devices which had been in situ for 0 months (see fig $1 a$ ), 4 months, 22 months, and 26 months (see fig $1 b-e$ ). Positions of K-alpha and K-beta lines of elements detected are shown.

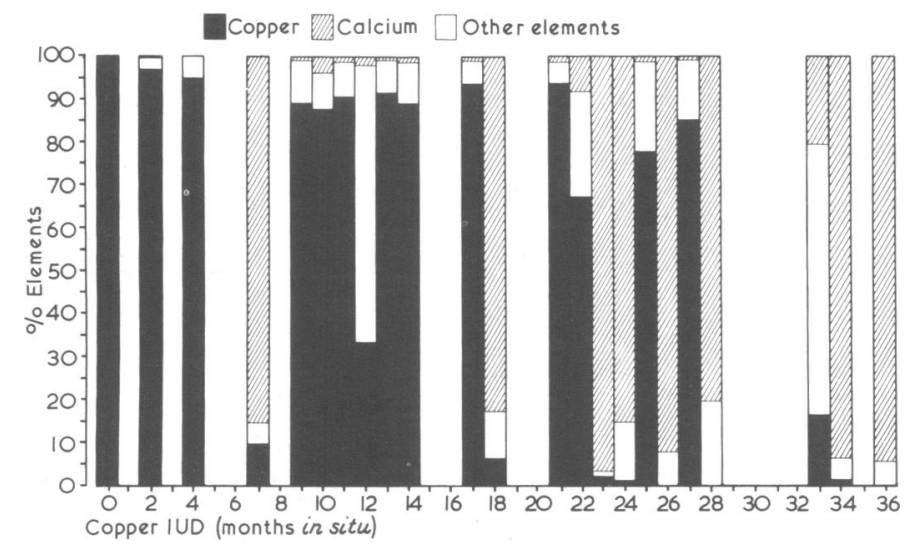

FIG 3-Percentages of copper, calcium, and other elements (sodium, potassium, sulphur, chlorine, and phosphorus) calculated from integral of each element present in spectra of 24 intrauterine devices. Unused device is shown at 0 months.

copper release. Presumably copper diffusion was renewed with the new device in the replacement group, thereby preventing pregnancy. The figures of Zipper et $a l^{1}$ on the comparative use of the $\mathrm{T}$ plain, $\mathrm{T} \mathrm{Cu}-\mathrm{A}$, and the loop $\mathrm{D}$ over two years suggested a greater pregnancy rate in the second year than in the first year for the copper $\mathrm{T} \mathrm{Cu}-\mathrm{A}$. Jain ${ }^{12}$ gave figures for three years' use of the copper $\mathrm{T} 200$ : the net annual pregnancy rate rose from 2.6 in the first year to 3.6 in the third year.

It is difficult to compare results obtained with different types of IUD, and results vary between centres. Many factors may be associated with both pregnancy and continuation rates, but double-blind trials of devices are often extremely difficult to operate. An increase in the pregnancy rate of even $1 \%$ in one year of use may, however, be critical in an attempt to provide IUDs that are both safe and effective.

The currently recommended time for using the copper 7 (two years) is based on an ultraconservative estimation of the amount of copper released from the device. As adequate amounts of copper are still present in the device after two years in utero it has been suggested that the insertion-removal interval might be extended to three to four years. Our own recommendation is that all the circumstances, including pregnancy rates, should be carefully examined in women who have had copper $7 \mathrm{~s}$ inserted. If the additional contraceptive effect of copper is to be of benefit then the period of maximum effectiveness may be limited to 18-24 months, and the replacement frequency of the coppercontaining devices should be reviewed. Snowden's findings in 317 pregnancies that occurred with an IUD in situ ${ }^{13}$ suggest that only a few (about $21 \%$ ) pregnancies proceed to full term. He found that $33 \%$ ended in spontaneous abortion, $35 \%$ were terminated, and $3 \%$ were ectopic. The outcome of the remaining $8 \%$ was not known. Pregnancy is thus a serious and sometimes tragic consequence of IUD failure, and more frequent renewal of copper-bearing IUDs may prevent this.

\section{ENDOMETRIAL CHEMISTRY}

Chemical studies of the uterus and endometrium give insight into the disturbances in metabolism caused by IUDs, which may in turn cause changes in the devices themselves. The main changes in the chemical composition of human endometrium produced by IUDs were a significant decrease of RNA and sodium and a fivefold increase in calcium during the proliferative phase and an increase of calcium, sodium, fucose, and the fucose:sialic acid ratio in the secretory phase. ${ }^{14}$

More recently Hernandez et $a l^{15}$ found that the subcellular distributions of trace metals in the human secretory endometrium were changed in the presence of copper IUDs. The sustained release of copper in utero induced significant increases in the magnesium, copper, and calcium concentrations and a decrease in zinc concentrations in women who had been wearing IUDs for six to 10 months. These findings support the idea that the effectiveness of copper may be associated with its cationic antagonistic action, in which zinc is displaced by copper from its specific binding sites. Moreover, these findings also show that even as early as $6-10$ months after insertion of the device endometrial concentrations of all trace elements except calcium come to equilibrium with the tissue concentrations of the elements but there is a significant retention of calcium.

After progressive calcification of the wire has occurred no copper can be detected in the intact older specimens, but, as seen in the cross-section (fig $1 e$ ), the copper wire is still present with virtually no change in its diameter. When calcium deposition is heavy large amounts of copper are still present, but diffusion through the calcium layer is greatly reduced.

$X$-ray microanalysis of the intact devices detects elements in the superficial layer only to a depth of a few micrometers. This is determined by the energy of the electrons and the absorption of the emitted $x$-rays. In our studies the electron energy remained the same $(30 \mathrm{keV})$ and the progressive reduction of copper with time in situ was due to the increasing thickness of the calcium layer. The eventual absence of a copper peak in the older, heavily calcified devices shows not only that the probe did not penetrate through to the copper layer but also that very little copper had diffused through the calcium layer.

\section{TERATOGENESIS}

Copper is toxic to animal embryos at low concentration, ${ }^{16}$ although Whittingham ${ }^{17}$ has shown that copper-containing devices do not have a direct toxic effect on the blastocyst, possibly because the protein in uterine secretion protects against the free copper ions.

Alderman ${ }^{18}$ recently measured the cord blood copper and caeroplasmin concentrations from a neonate conceived in the presence of a copper 7 IUD. The serum copper concentration was 2-5.5 times the normal level for neonates of equivalent gestational ages and the serum caeroplasmin was 3.5-8 times the normal concentration. Maternal copper and caeroplasmin concentrations were normal. Barrie ${ }^{19}$ described two infants with unusual limb reduction malformations born to mothers who had been fitted with intrauterine devices (a Grafenberg ring containing copper and lead and a Dalkon shield containing $12 \%$ barium sulphate, $0.5 \%$ copper dust, and $1 \%$ anhydrous copper 
sulphate), but these devices were not wound with copper wire. This report must be viewed in the context that limb reduction deformities occur in about 1 in 5000 of live births.

We have seen several cases of spontaneous abortion occuring after conception in the presence of an IUD. One such case was an anencephalic fetus of 11 weeks' gestation. As anencephaly and spina bifida are present in about $5 \%$ of the spontaneously aborted fetuses we see, 20 the importance of our observation must be tested in larger series of pregnancies occurring with IUDs in situ. Our finding of progressive calcification suggests, however, that any teratogenic effects attributable to copper may be limited to the precalcification period. Nevertheless, despite the reassuring experimental work on rodents and human tissue cultures, ${ }^{21}$ it is unrealistic on the available evidence to dismiss the possibility of a teratogenic effect from a retained intrauterine device. More information is urgently needed on the outcome of pregnancies complicated by the presence of IUDs.

\section{FUTURE STUDIES}

New types of IUD, such as those that depend on the sustained release of progesterone, are being developed. In view of the calcium deposition that may occur the efficiency of such IUDs should be carefully evaluated. A study of drug or copper levels in the cervical mucus while the device is still in situ would be a simple and accurate way of indicating whether the substance was still being released. It might also detect women in whom the deposition of calcium is particularly rapid. Possibly conception in the presence of an IUD that releases metal or a drug is more common in women who suffer rapid calcification.
Grant for their help and discussions during the progress of this work, and the medical and nursing staff of the Lothian Health Board Family Planning Services for their help and for collecting the devices. We are indebted to Mr A R Ross and Miss C Gray for their expert technical help.

\section{References}

1 Zipper, J A, et al, American fournal of Obstetrics and Gynaecology, 1969, $105,2274$.

2 Zipper, J A, et al, American fournal of Obstetrics and Gynaecology, 1971, $109,771$.

${ }^{3}$ Middleton, J C, and Kennedy, M, Contraception, 1975, 11, 209.

4 Teitze, C, and Lewit, S, Studies in Family Planning, 1970, 55, 1.

${ }^{5}$ Hagenfeldt, K, Contraception, 1972, 6, 37.

${ }^{6}$ Daunter, B, and Elstein, M, Journal of Obstetrics and Gynaecology of the British Commonwealth, 1973, 80, 644 .

7 Tatum, H J, Clinical Obstetrics and Gynecology, 1974, 17, 93.

${ }^{8}$ Gupta, P K, Malkini, P K, and Bhasin, K, Contraception, 1971, 4, 375.

- Gibor, Y, Population Report. Washington, George Washington University Medical Centre, 1973.

${ }^{10}$ Zielske, S, et al, Contraception, 1974, 10, 651.

11 Newton, J, British Medical fournal, 1977, 1, 197.

12 Jain, A K, Contraception, 1974, 11, 243.

13 Snowden, R, British Medical fournal, 1976, 1, 770.

${ }^{14}$ Rosado, A, et al, American fournal of Obstetrics and Gynecology, 1972, 114, 88.

15 Hernandez, O, et al, Contraception, 1975, 11, 451.

16 Whitten, W K, Advances in Biosciences, 1971, 6, 129.

17 Whittington, D G, in Society for Study of Reproduction, 5th Annual Meeting. Cambridge, Reproduction Research Information Ltd, 1972.

18 Alderman, B, British Medical fournal, 1975, 1, 770.

19 Barrie, H, British Medical fournal, 1976, 1, 488.

${ }^{20}$ Bell, J, and Gosden, C, in preparation.

${ }^{21}$ Jones, R W, Gregson, N M, and Elstein, M, British Medical fournal, 1973, 2, 520 .

(Accepted 2 December 1976)

\title{
Liver-cell-membrane autoantibody specific for inflammatory liver diseases
}

\author{
U TAGE-JENSEN, W ARNOLD, O DIETRICHSON, F HARDT, U HOPF, \\ K H MEYER ZUM BÜSCHENFELDE, J O NIELSEN
}

British Medical fournal, 1977, 1, 206-208

\section{Summary}

With an immunofluorescence technique using rabbit hepatocytes isolated by a non-enzymatic method an autoantibody directed against liver-cell-membrane was identified. Sera from 361 patients with various liver diseases and 274 patients with primary non-hepatic diseases-many associated with non-organ-specific auto-

\footnotetext{
Second Department of Internal Medicine, Kommunehospitalet, Department $M$, Rigshospitalet and Division of Hepatology, Hvidovre Hospital, Copenhagen, Denmark

U TAGE-JENSEN, $M D$, registrar

F HARDT, $M D$, senior registrar

J O NIELSEN, MD, senior registrar

O DIETRICHSON, MD, senior registrar

Second Department of Internal Medicine, University of Mainz, Mainz, West Germany

W ARNOLD, MD, senior registrar

U HOPF, MD, senior registrar

K H MEYER ZUM BƯSCHENFELDE, MD, professor
}

antibodies-were examined. The antibody (LMA) was found in 27 out of 72 patients with hepatitis-B-surface antigen (HBsAg)-negative chronic active hepatitis and in 17 out of 28 patients with $\mathrm{HBs}$ Ag-negative nonalcoholic cirrhosis. Only two patients had LMA and HBsAg, and both had chronic active hepatitis. One patient with extrahepatic disease was found to have LMA, and this patient had biochemical evidence of liver disease.

Hence there is a close correlation between the presence of LMA and HBsAg-negative chronic inflammatory liver disease and its detection may help in diagnosis.

\section{Introduction}

There are several different causes of chronic liver disease. Serologically most patients with chronic active liver disease (CALD) may be separated into two groups: one with circulating hepatitis B surface antigen $(\mathrm{HBsAg})$ and the other with nonorgan-specific autoantibodies. ${ }^{1-3}$

An autoimmune mechanism may be concerned in the pathogenesis of the liver damage in patients with circulating autoantibodies. ${ }^{4}$ In these patients, however, the meaning and importance of autoimmunity as shown by the presence of non-organ-specific 